\title{
Istorie Fiorentine de Maquiavelo: una primera definición moderna de corrupción
}

\author{
Eloy García \\ eloygarc@gmail.com
}

\section{Resumen}

La traducción al español de las Historie fiorentine de Nicolás Maquiavelo (1525) proporciona una magnífica ocasión para reflexionar sobre un trabajo del secretario florentino tan fundamental como olvidado, y de enorme trascendencia en el posterior pensamiento de Montesquieu, Rousseau y Constant. Tres son las ideas claves de la aportación de Maquiavelo. Primeramente, la idea de la Historia como instrumento humano al servicio del conocimiento político, idea tomada de Polibio (y que nada tiene que ver con el círculo cerrado de los griegos) y articulada en torno a las categorías de ascensión y caída ("disminución», progreso y decadencia) de las naciones. En segundo lugar, Maquiavelo concibe el declive - o decadencia - como fenómeno asociado a la corrupción, entendida a su vez como proceso sociológico colectivo de degradación de la regulación: en esta perspectiva, «aquel que abandona lo que hace por aquello que debería hacer se precipita a su ruina en lugar de a su provecho». Por último, la historia de Florencia es, para Maquiavelo, el ejemplo de lo que es necesario evitar: un anti-ejemplo. Florencia no era libre porque estaba corrompida, tanto en lo interior (en lo civil), como en lo exterior (lo militar), lo cual le impedía practicar un autogobierno en el que estuviera involucrada toda la sociedad civil.

Palabras clave: historia, política, ciclo, círculo, ascenso, disminución y decadencia, progreso y declive, virtud y fortuna, corrupción, ejemplo y anti-ejemplo, milicia, cívico, autogobierno, libertad política.

\begin{abstract}
The Spanish translation of Machiavelli's Historie fiorentine (1525) provides an excellent occasion to reconsider a fundamental yet widely neglected work by the Florentine secretary which was to be essential in the thought of such remarkable authors as Montesquieu, Rousseau and Constant. Three key ideas are put forward in this work. Firstly, the idea of History as a means to acquire political knowledge, an idea based on the categories of the ascent and the decline of nations borrowed from Polybius (divergent, though, from the ancient Greeks'idea of history as a «closed circle»). From this perspective, «decline» (or «decadence») is conceived as a phenomenon associated with corruption, viewed, in turn, as a social, collective process of law degradation in which «him who departs from what he does to do what he must do, seeks his own ruin instead of his own benefit». Finally, from Machiavelli's point of view, the history of Florence is considered as an example of what should never be done, an anti-example: since Florence was corrupted both internally (civilly) and
\end{abstract}


externally (military), any form of self-government based on the participation of all civil forces was impossible, which accounts for Florence's loss of freedom.

Key words: History, Politics, Cycle, Circle, Ascent, Decrease and Decadence, Progress and Decline, Virtù and Fortune, Corruption, Example and Anti-example, Militia, Civic, Selfgovernment, Political Freedom.

\section{Las circunstancias de la redacción de Historia de Florencia}

Es posible que Historia de Florencia ${ }^{1}$ sea el libro que menos interés suscite entre los estudiosos actuales de Nicolás Maquiavelo. Sin embargo, no se trata de una obra menor, ni por la temática que le sirve de argumento, ni por las expectativas que el propio secretario florentino cifró en su aparición. Antes al contrario, conviene señalar que tanto las complejas implicaciones subjetivas que rodearon su elaboración, como el papel que le corresponde en el conjunto del pensamiento de Maquiavelo, nos sitúan ante un ensayo crucial para su autor, de enorme repercusión en clásicos posteriores de la talla de Montesquieu, Rousseau o Benjamin Constant.

Aunque no parezca un sinsentido sugerir que el propósito de escribir la historia de Florencia debió rondar en la cabeza de Maquiavelo desde los gozosos tiempos de la República de Piero Soderini (1498-1512), lo cierto es que éste libro surge fruto de un encargo efectuado en 1520 por Julio de Medici, futuro Papa Clemente VII, en el marco del Studio Fiorentino. Nos hallamos, por consiguiente, ante una encomienda pública que procede del adversario, de los hombres que ocho años atrás habían arrojado a nuestro personaje de la política activa y prohibido su acceso a Palazzo Vecchio.

Es sabido que Maquiavelo nunca se resignó a la desgracia. Hasta el final de sus días, retuvo el recuerdo de las cosas perdidas, y luchó por recuperar su lugar entre aquel mundo para el que había nacido. Y la prueba más elocuente estriba en que, su primer libro tras el despojo, El Príncipe (1513), fue dedicado a Lorenzo de Medici, en la vana esperanza si no de recobrar el poder, sí al menos de ser escuchado por quiénes lo ocupaban. Ahora, gracias a incesantes ruegos a los contados amigos que le restaban en el entourage gobernante, ante Maquiavelo se abría por fin una oportunidad que no quería ni debería desperdiciar.

Pero la chance conllevaba un desafío personal e intelectual de primera magnitud. ¿El republicano que en los Orti Oricellari leía a sus correligionarios capítulos escogidos de los Discorsi, ${ }^{2}$ podría acaso narrar la historia de una ciudad vencida y dominada por los Medici? ¿Traicionaría Maquiavelo sus ideales para acercarse al poder, o sabría aprovechar la ocasión que le brindaba la fortuna para instruir al poderoso en la disciplina de la virtù?

1. Nicolás Maquiavelo, Historia de Florencia, traducción de Félix Fernández Murga, estudio de contextualización Felix Gilbert, Madrid: Tecnos, 2009.

2. F. GILBERT, «Bernardo Rucellai and the Orti Oricellari. A Study on the Origen of Modern Political Thought", Journal of the Warburg and Courtauld Institutes, 1949. 
Las opiniones al respecto discrepan. Hay quién, tras las soflamas de los enemigos de los Medici que se reiteran en las páginas del libro, cree detectar sentimientos de hostilidad encubierta del autor hacia su benefactor, ${ }^{3}$ lo que, sin pretenderlo, quizás equivalga a dar pábulo a tesis que habrían hecho las delicias de Leo Strauss y sus seguidores: el carácter secreto y pseudo criptográfico de la escritura de Maquiavelo. ${ }^{4}$ Pero con independencia de que en determinados pasajes el recurso a semejante uso se encuentre de sobra acreditado, ${ }^{5}$ la propia existencia del dilema está supeditada al significado que se atribuya al mensaje que encierra el discurso de Maquiavelo. Así, mientras que para quienes como Meinecke tienen en el florentino al teórico de la razón de Estado, ${ }^{6}$ El Príncipe e Historia de Florencia responden a una misma línea lógica en la que no hay quiebra ni contradicción alguna, para aquellos otros que ven en Maquiavelo al humanista cívico angustiado ante la difícil supervivencia de la República en un mundo que presiente la modernidad, ${ }^{7}$ el compromiso de escribir la Historia representa un acertijo, cuando no una anomalía, cuyo significado urge resolver.

Nada tiene de extraño pues, que fueran autores que mantienen las posiciones de Sasso, ${ }^{8}$ o de Gilbert, ${ }^{9}$ los que prácticamente en solitario, sintieran la conveniencia de acometer el estudio de Historia de Florencia como una tarea digna de un tratamiento especifico y singularizado que, no obstante, respete la unidad substancial de la obra de Maquiavelo.

3. Por ejemplo, la advertencia de Nicolas de Uzano en contra del exilio de Cosme de Medici (Historia, cit., lib. IV, cap XXVII, p. 223-224), el discurso dirigido al duque de Milán (ibidem, lib. V, cap. VIII, p. 247-249), o los discursos de los expatriados florentinos al Doge (ibidem, lib. V, cap. XXXI, p. 266-268).

4. L. STRAUSS, La persecución y el arte de escribir, Madrid: Amorrortu, 2009 (el original de 1952), y Meditación sobre Maquiavelo, Madrid: Instituto de Estudios Políticos, 1964 (original de 1958); H. C. Mansfield, Machiavelli's Virtue, Chicago: University of Chicago Press, 1998.

5. Caso del discurso de Pedro de Medici a sus seguidores (Historia, cit., lib. VII, cap. XXIII, p. 382). En éste mismo sentido también, ver la cuidada ambigüedad de una frase de la Dedicatoria: «Y, aunque bajo esos ilustres hechos [de los Medici] se hubiera escondido, como algunos dicen, alguna ambición contraria al bien común, como a mi no me consta eso, no tengo porque hablar de ello" (ibidem, p. 20).

6. F. MEINECKE, La idea de razón de Estado en la Edad moderna, Madrid: Centro de Estudios Constitucionales, 1952 (original de 1924). Una crítica no sospechosa que deja al descubierto que en el Maquiavelo de Meinecke, por paradójico que pueda parecer, no hay vestigio alguno de la tesis de la razón de Estado, en Carl SCHMITT, Zu Meinecke idee Staastraison (1926) reeditado en Positionen und Begriffe 1923-1939, Berlín: Duncker \& Humblot, 1940.

7. La primera presentación de esa lectura en España, Miguel Ángel Granada, Maquiavelo, Barcelona: Barcanova, 1981.

8. G. SASSO, Niccolò Machiavelli, Bolonia: Il Mulino, 1993. El segundo volumen está dedicado a la historiografía.

9. F. GILBERT, «Machiavelli’s Istorie Fiorentine» (1972), incluido ahora en la traducción española citada. 


\section{La Historia de Florencia en el contexto de los escritos de Maquiavelo}

Como advierte Helena Puigdomenech, Maquiavelo siempre estuvo escribiendo el mismo libro, ${ }^{10}$ lo cual no es óbice para admitir a renglón seguido que, ese libro estaba integrado por numerosos y diferentes capítulos que, en Historia de Florencia aparecen organizados en torno a tres problemas bien identificados: cierta idea de Historia que implica una trascendental ruptura con la teoría circular de Polibio, el primer esbozo de una categorización moderna de corrupción, y el intento de construir un ejemplo moral desde la noción de antimodelo.

\section{II.1. La Historia: una lectura de la Política en el tiempo que depara enseñanzas.}

Resulta ilustrativo que, a punto de formalizar el encargo de la Historia, y poco antes de enfrascarse en la gestación de un trabajo que iba a ser laborioso, prolijo y extenso, Maquiavelo se distrajera redactando La vita de Castruccio Castracani (1520), un breve y delicioso opúsculo que no siempre ha sido correctamente ponderado. Todo se explica en la medida que Castruccio estaba destinado a servir de ensayo de redacción y, lo que todavía apunta más pistas, de taller de prueba en que depurar los supuestos teóricos que luego manejaría en la Historia y que le permitirán dar un formidable salto en su argumento. Y es que, Castruccio no es otra cosa que El Príncipe de Maquiavelo en acción: un héroe emplazado en un relato, real o fabulado, que trascurre en movimiento, es decir, en la Historia. Un protagonista medio recreado, al que la fortuna impide terminar bien. En la reflexión maquiavélica, Castruccio se perfila, por tanto, como puente de tránsito en el camino que, por mediación de Historia de Florencia, conduce a la Historia.

En eso se distinguen las dos obras iniciales de Maquiavelo de esta tercera, y hace que también ella sea una auténtica labor de madurez, en su época a años luz de cualquiera de su género. ${ }^{11}$ Si El Príncipe versa sobre el hecho del héroe solitario (el ser excepcional) que domina lo nuevo dándole forma según valores que le son privativos, y los Discorsi es una exploración inconclusa de los factores constitutivos de una República formada en la virtú, la Historia narra la existencia política de su Ciudad en el lenguaje del tiempo secular. Lo dinámico sustituye a lo estático, la construcción del arquetipo cede paso a la reflexión sobre el movimiento y sus reglas, la preocupación por captar los fenómenos de lo contingente remplaza a la indagación sobre la gobernabilidad.

La superación de la visión de la existencia como eterna recurrencia circular dónde cabe movimiento pero no la novedad, es el punto de arranque de la

10. H. Puigdomenech, «Estudio preliminar», en N. Maquiavelo, La Mandragora, Madrid: Tecnos, 2008, p. XLVIII-XLIX.

11. Maquiavelo desde el principio establece en el Prohemio distancias con sus predecesores, Leonardo Bruno y Poggio Bracciolini, que van más allá de lo que expresamente les imputa: limitarse a conocer de los conflictos externos de la ciudad, olvidando la narración de sus querellas internas. 
gran aportación de la Historia que marca un hito en la forja de la autoconciencia maquiavélica. Abstracción hecha de las formidables polémicas que suscitaron las referencias a Polibio recogidas en los Discorsi (1517), ${ }^{12}$ es fácil intuir que, en ese primer libro, Maquiavelo juega con la rueda polibiana sin jamás llegar a hacerla suya, pero sin tampoco refutarla de manera clara. Parece vacilar, meditar perplejo ante lo que acaba de conocer de primera mano. En cambio, en la posterior Historia (1520-5), no hay duda: Polibio ha sido absorbido, sobrepasado y reutilizado, hasta el extremo de que, el autor, seguro de lo que dice, se permite ironizar al efecto. ${ }^{13}$ El ciclo se ha desprendido del círculo.

El antiguo servidor de la Signoria se afirma en la certeza de que la historia consiste en una colección de secuencias inmersas en un fluir irresistible que, ni se halla escrito ni concluye inexorablemente en reinicio. ${ }^{14}$ Son los hombres con su hacer o deshacer, los que, enfrentándose a la fortuna, pueden servirse de los vaivenes de la vida para recalar en una orilla u otra. Frente a esa fuerza irresistible, la virtù es la única arma al alcance de los seres humanos. Ahora bien, para Maquiavelo ¿en qué consiste, de qué trata en concreto la Historia?

Definir la Historia como "verità effettuale delle cose» en el tiempo, no equivale a enjuiciar la realidad con imparcialidad. En la historia de Maquiavelo no existe el relato neutral, no hay pretensión de objetividad ni de abarcar íntegramente lo acaecido. La Historia es Política, y como Política sirve para seleccionar series de acontecimientos relevantes según la intencionalidad ideológica del autor, para extraer enseñanzas. No estamos frente a una historiografía incipiente, sino ante la primera toma de conciencia del significado fenomenológico de la Política en un mundo construido secularmente. El Maquiavelo historiador, es un estudioso de la Política que proyecta en dimensión de pasado los cambiantes hechos del vivere civile de los florentinos, buscando beneficios de presente: reconducir lo que conoce a los patrones ordenadores que correspondan, o entregar a un ordinatore lo que por radicalmente nuevo considera anómico.

Aunque Maquiavelo tenga siempre presente la posible irrupción de la forza estraordinaria capaz de desatar lo desconocido (la invasión francesa que en 1494 arrasó con todo en Italia), lo que le preocupa en la Historia es el discurrir de la política en el mundo ordenado. Ese mundo pertenece a los

12. Sobre ésta polémica, Miguel Ángel Granada, Maquiavelo. Antología, Barcelona: Península, 2002, p. 413 y s.

13. Historia, cit., lib. III, cap. XIX, p. 171-172.

14. «Invadidos por los bárbaros [...] lo mismo Italia que las demás provincias romanas [...] no sólo cambiaron de gobierno y de jefes sino que cambiaron también de leyes, de costumbres, de modo de vivir, de religión, de lengua, de manera de vestir, y hasta de nombre [...] De todo esto derivó, de una parte, la ruina de muchas ciudades y, por otra, el nacimiento y auge de otras muchas [...] entre las de nueva fundación estaban Venecia, Ferrara, Siena [...] En medio de estas ruinas y de estos pueblos surgieron nuevas lenguas. Han cambiado también de nombre no sólo las provincias, sino también los lagos, los ríos, los mares y hasta los hombres [...] ni fueron menos importante el de religión", ibidem, lib. I, cap. V, p. 36. 
"ordini e modi», los patrones dotados de formas que encauzan el obrar político, y que resumen el entramado de usos, costumbres, leyes, modos de vida, pensar y obrar que estructuran y dan existencia a una colectividad moderna. ${ }^{15}$ Son factores imprescindibles para un Maquiavelo que, en la medida en que no ha renunciado completamente a Polibio, se permite reinsertar de manera instrumental el ciclo en un contexto muy diferente, regido por los ordini.

Es así como las secuencias temporales que agrupan el devenir pasan a estar presididas por momentos álgidos y momentos de caída, de ascenso y decadencia que no forman parte de un círculo eterno y ajeno a lo humano. Son los hombres los que con sus acciones respetan o violentan la lógica que inspira el patrón (ordine) de conducta que guía su comportamiento, determinando el ascenso o declive de las sociedades. Y en esa circunstancia, el mecanismo que mueve el ciclo del ascenso al descenso es la resultante de la degradación de los ordini por el hacer humano. ${ }^{16}$ En éste sentido y como lo atestiguan la lectura del las introducciones a los libros III al VII, la única secuencia histórica que en realidad interesa a Maquiavelo, es la comprendida en el lapso temporal que transcurre entre la virtù que se expresa en el hecho fundacional presente en el origen fundacional de Florencia, hasta el estado de corrupción por aquél entonces imperante.

\section{II.2. Sociología de la Corrupción}

Para las teorías que beben en Aristóteles, la corrupción viene asociada a la degeneración de un elemento particular que, ignorando su naturaleza parcial, aspira a encarnar el fin universal que sólo corresponde al conjunto de la suma de cuerpos. Para Maquiavelo, sin embargo, la corrupción es un estadio sociológico de ruina o degradación de la naturaleza original de los ordini en que se articula una comunidad política que, en el tiempo y a través de sucesivas fases, ha terminado emergiendo como una segunda realidad enmascarada en las apariencias de la primera.

Se trata de dos planteamientos diametralmente opuestos de la idea de corrupción; filosófico uno, sociológico el otro. La paternidad de este último es imputable en buena medida a Maquiavelo que, en Historia de Florencia ofrece implícita una definición moderna de corrupción. Maquiavelo percibe la corrupción como una fenomenología social: una dinámica colectiva por la cual el cuerpo o modelo que ordena y da formas a la comunidad, desconectado del fin que lo alentaba, va perdiendo su fuerza conductora, su estructura distintiva, su regularidad de comportamiento y la conexión entre fondo

15. Francisco Javier CONDE, El saber político de Maquiavelo, Madrid: Revista de Occidente, 1976, p. 91 y s.

16. "Como la naturaleza no ha dado a las cosas terrenas el poder detenerse, cuando éstas llegan a la cima de su perfección, al no tener ya de llegar más alto, no les cabe otro remedio que declinar» Historia, cit., lib. V, cap. I, p. 237. 
y representaciones. El alma ha abandonado el cuerpo y el patrón que encuadraba el orden humano, en tanto que materia informe, deriva en irregular, en incomprensible, y resulta incapaz de imponer proceder ninguno. No es posible saber a que atenerse, y como nada es lo que dice ser, «quien deja de hacer lo que hace por lo que debe hacer, corre a la ruina en lugar de beneficiarse». ${ }^{17}$

La corrupción significa una escisión ontológica entre el ser y sus manifestaciones, inducida por la acción humana. Surge de una mutación del patrón que identifica la conducta social, provocada por un obrar cotidiano que no responde a las prescripciones de sus ordini. La existencia política no se reconoce en una manera de operar que, a la vez, no guarda correlato con lo que dice contener dentro. Su naturaleza originaria ha sido devorada por una fenomenología contraria a su ser, sin que ello haya supuesto necesariamente el abandono de las apariencias o envolturas anteriores que, durante algún tiempo permanecen subsistiendo, caso en Florencia de aquella «libertad, de la que lo único que se respetaba era el nombre». ${ }^{18}$

La naturaleza se ha corrompido porque lo que los hombres hacen en su vida social, difiere de lo que tienen por norma; porque se ha consumado un decalage entre lo que se dice que se hace y aquello que los seres humanos se sienten en la obligación de hacer. Por eso, la corrupción es ante todo un estado de degradación moral de carácter negativo: son los hombres los que con su conducta inmoral hacen factible la desnaturalización de los ordini. Pero también son los hombres los que, con su actitud inmoral de guiarse por las manifestaciones de la realidad y no por los contenidos de esos ordini que todavía continúan formalmente reconociendo, tornan en irremediable tamaño estado de cosas.

La corrupción en Maquiavelo no se concibe como una patología susceptible de ser combatida con los remedios de una legalidad a la que su propia aplicación desvirtúa, uno por su generalizada extensión, y dos por la existencia de un segundo orden admitido como tal. La corrupción no es un ilícito penal, sino un estado social colectivo en el que los ordini son deliberadamente desobedecidos por unos hombres que, consciente o inconscientemente, rinden tributo ya a otros señores.

\section{II.3. El anti-ejemplo: Corrupción y Declive de la libertà en Florencia}

No es casual que el término que más veces se repita en el Prohemio sea «ejemplo». Narrar la historia de Florencia como modelo cargado de sentido moral,

17. N. Maquiavelo, El Príncipe, cap. XV. Traducción libre del autor de este trabajo desde el texto establecido por Giorgio Inglese. Para consultar el texto de Inglese, véase la edición francesa de FOURNEL y ZANCARINI, París: PUF, 2000. Una versión diferente en la excelente traducción española de Helena Puigdomènech, El Príncipe, Madrid: Tecnos, 1988, p. 61.

18. Historia, cit., lib. IV, cap. I, p. 191. 
es la gran ambición de Maquiavelo. Ahora bien, nos hallamos en presencia de un ejemplo negativo, no de un modelo a emular. Sus textos enseñan lo que no hay que hacer, no lo que se debe hacer. ${ }^{19}$ La Historia de Florencia recoge el contra-ejemplo de una ciudad cuyos habitantes habían perdido la libertà interior y exterior imprescindible para dominar sus propias acciones, que siempre estuvieron mediatizadas por poderes exteriores o por flaquezas internas, y eso causó su declive.

A la muerte de Federico II, Florencia ordenó su vivere libero y su defensa sobre la virtì, instituyendo una organización cívica y militar que pronto dio fuerza y prestigio a la ciudad. ${ }^{20}$ Pero no tardó en anidar la corrupción en sus instituciones. Las discordias civiles vinieron instrumento de exclusión política con los terribles efectos que ello trajo para una Ciudad que, en la implicación activa de todos sus ciudadanos, tenía la piedra maestra de su autogobierno. ${ }^{21}$ Las «sètte» desplazaron a las facciones, y los modi privati de acceso a la fama, tomaron el lugar de las vie publiche. ${ }^{22}$ La República se hizo parte y la Ciudad se rompió por dentro. Mientras por fuera el declive de la virtù guerrera entregó las armas a los condottieri ${ }^{23}$ que, convirtieron la gue-

19. «Si alguna lección resulta útil a los ciudadanos que gobiernan las repúblicas es la que expone los motivos de los odios y las rencillas de una ciudad, a fin de que, escamentados en el mal ajeno, puedan dichos ciudadanos mantenerse unidos. Si el ejemplo de cualquier república es capaz de mover, mucho más mueven y mucho más útiles son los que se refieren a la propia patria [...] ningún otro ejemplo demuestra tan claramente la fuerza de nuestra ciudad como el que se desprende de esas mismas divisiones», ibidem, Prohemio, p. 24. «Y si al describir los hechos ocurridos en este mísero mundo no podrá hablarse de fortaleza en los soldados, ni de la virtù en los capitanes, ni de amor patrio en los ciudadanos, podrá verse en cambio de qué astucias y artimañas se sirvieron tanto los príncipes como los soldados y los jefes de las repúblicas para conservar el prestigio que no se habían merecido. Conocer todo esto quizás sea no menos útil que conocer las glorias antiguas, pues si éstas estimulan a los hombres generosos para que las imiten, lo otro les estimulara a evitarlo y corregirlo", ibidem, lib. V, cap. I, p. 239.

20. Ibidem, lib. II, cap V y VI, p. 85-86.

21. Gisela Bock en su «Civil Discord in Machiavelli's Istorie fiorentine» incluido en BocK; SKInNer; VIroli (eds.), Machiavelli and Republicanism, Cambridge: Cambridge University Press, 1990, no insiste en que la idea de autosuficiencia política que informa a la Ciudad, y que fundamenta el deber de ciudadanía, es la víctima final de este proceso de exclusión. Algo que deja muy claro Maquiavelo en el discurso del ciudadano que movido por el amor a la patria pretende poner fin a los desordenes posteriores a 1366. Cfr. Historia, cit., lib. III, cap. V, p. 146-149.

22. «Hay divisiones que son perjudiciales para las repúblicas, pero hay otras que son beneficiosas. Resultan perjudiciales las que van acompañadas de sètte o partidismo, mientras que son beneficiosas las que los evitan [...] conviene saber que los procedimientos mediante los que suelen los ciudadanos lograr fama son de dos tipos: vie publiche y modi private [...] Se consigue fama pública venciendo batallas, desempeñar embajadas con celo y prudencia o proporcionar a la república sabios consejos. Privadamente [...] haciendo favores a éste o aquél ciudadano, defendiéndole de la arbitrariedad de los magistrados, socorriéndolos económicamente, concediéndoles honores no merecidos, ganarse a la plebe con festejos y dádivas públicas», ibidem, lib VI, cap I, p. 352.

23. «También los florentinos se veían (sin armas propias) porque, habiendo destruido a la nobleza con las frecuentes disensiones y quedando aquella república a merced de hom- 
rra en una farsa ${ }^{24}$ del estilo de aquella tremenda batalla de Zagonara, dónde la única víctima cayó del caballo. "De éste modo - y a pesar de que sus ciudadanos, llenos de virtù, persistían una y otra vez en sus esfuerzos - ${ }^{25}$ Florencia fue haciéndose, cada vez más baja y más abyecta». ${ }^{26}$

Es evidente que Maquiavelo no busca exaltar los grandes logros del pasado como factor que invite a imitación en el presente. Se recrea en el fracaso, en la incapacidad histórica de la signoria para disfrutar de libertà. Su Historia es la historia del Descenso, no del Ascenso de Florencia y de Italia en general, $y$ posee un fin pedagógico e instructivo que queda perfectamente claro tanto aquí, como en el otro libro que escribirá al mismo tiempo que éste, el Arte Della Guerra (1521).

Y es así como, sirviéndose del juego de antinomias en cascada que tan bien sabía administrar, Maquiavelo nos sitúa ante la Guerra como alternativa inmediata a la corrupción y por tanto, a la decadencia. Sólo recuperando la virtù guerrera será posible recuperar la virtú política, porque ambas son lo mismo (en la milicia como en la vida política es necesario el concurso de todos los estratos de la Ciudad). ${ }^{27}$ La milicia ciudadana es la alternativa a la corrupción civil. Desde ese estado de corrupción, Maquiavelo lanza su remedio: la acción guiada por la virtù, o sea, "ridurre i principi».

Historia de Florencia participa de esta suerte del ideario patriótico que se expresa en el tantas veces repetido adagio cívico: «amare la propria patria piú della propria anima». ${ }^{28}$ Algo que dicho así, no podía repugnar a los Medici ni traicionar el pensamiento del autor: todos tienen cabida en la Ciudad. ${ }^{29}$ Maquiavelo procura servir a quien le paga, sin enmendar un ápice sus convicciones.

bres nutricati nella mercancía tenían que seguir las órdenes y fortuna ajena (que) se vestían no por el deseo de gloria sino para vivir más ricos o más seguros. Todos [...] se habían puesto de común acuerdo y habían formado una coalición hábilmente organizada [...]se las arreglaban de manea que perdieran tanto el uno como el otro contendiente. Al final redujeron a tal estado de viltà esta profesión, que cualquier mediano capitán, en el que hubiera brotado una ligera sombra della antica virtù, los habría puesto en ridículo.», ibidem, lib. I, cap. XXXIX, p. 75.

24. "Tampoco pueden llamarse guerras aquéllas en las cuales ni los hombres se matan, ni las ciudades son saqueada, ni se destruyen los Estados», ibidem, lib. V, cap. I, p. 238.

25. Era tal la «virtù de los florentinos, y el poder de su ingenio, y su empeño en hacerse grandes y engrandecer a su patria, que los males conseguían exaltarla más de lo que habían conseguido abatirla los contratiempos que la habían aquejado [...] tanto habrían abundado en ella la virtù de las armas y la fuerza del ingenio", ibidem, Prohemio, p. 24-25.

26. Ibidem, lib. III, cap I, p. 142.

27. Resulta significativo que la única obra publicada de Maquiavelo, en el sentido actual de dada a la imprenta para que la adquiera el público, sea el Arte Della Guerra. También lo es que fuera escrita en forma de diálogo.

28. «Si el ejemplo de cualquier república es capaz de mover, mucho más mueven y mucho más útiles son los que se refieren a la propia patria», ibidem, Prohemio, p. 24.

29. Esa es la propuesta que se defiende en su Discurso sobre las cosas de Florencia de 1520, encargado por Julio de Medici a modo de informe de qué hacer para estabilizar el gobierno de Florencia. 


\section{Releer ahora Historia de Florencia}

Lo que hoy llamamos Historia de Florencia es cuanto nos ha quedado de un proyecto inacabado que probablemente fuera redactado en dos grandes atacadas. ${ }^{30}$ Así lo indica Maquiavelo en la dedicatoria. ${ }^{31}$ Pero más allá de las intenciones del autor, su obra reaparece en un momento en que la crisis de las ideologías ha reabierto los grandes problemas que hubo de afrontar el hombre al inicio de la Modernidad.

En este sentido, nada tiene de extraño que la Historia se revele como un libro abierto que, tras aburridos y minuciosos detalles, que en la versión española amortigua la excelente prosa de Fernández Murga, deja entrever los graves retos que acosan tanto a la Historia como la Política de nuestros días, y para los que no parecen tener respuesta ni las explicaciones holistas de la vida, ni conceptos como Revolución, Poder Constituyente o incluso, tal vez, Constitución. Estamos, en suma, ante un libro que se sitúa en relación de genealogía y no de arqueología con nuestro confuso presente.

30. Gilbert sostiene que mientras los actuales libros II a VI fueron escritos antes de la rendición provisional de cuentas que Maquiavelo efectuaría en el verano de 1522 ante el cardenal de Medici, los capítulos que los introducen, junto con los títulos I, VII y VIII, más el Prohemio, serían una obra posterior.

31. En la dedicatoria presenta el trabajo como una recopilación dice expresamente «trataré de continuar mi empresa», ibidem, p. 21. Se conservan, y son conocidos hace mucho, fragmentos de lo que parece ser estaba previsto que fueran capítulos IX y X. 